\title{
Strengths and challenges of community-based clinical training as viewed by academics at the University of KwaZulu-Natal, Durban, South Africa
}

I Moodley, MSc (Dent); S Singh, PhD

Discipline of Dentistry, School of Health Sciences, University of KwaZulu-Natal, Durban, South Africa

Corresponding author: I Moodley (moodleyil@ukzn.ac.za)

\begin{abstract}
Background. Community-based education (CBE) is seen as a valuable tool in transforming health professions education by aligning clinical training with graduate competencies and needs of the health system. However, academics involved in the implementation have varied views.

Objectives. To explore the experiences and views of academics involved in community-based training in the College of Health Sciences at the University of KwaZulu-Natal, Durban, South Africa.

Methods. This qualitative study used interviews and focus group discussions consisting of a purposively selected sample of academics. The interviews were audio taped, transcribed and analysed using thematic analysis.

Results. Three main themes emerged from the data analysis: the strengths of CBE, challenges experienced in implementation and academics' suggestions concerning challenges. The strengths included benefits to the institution, students, health system and communities. The main challenges experienced were insufficient support from the institution and the Department of Health (DoH). Suggestions were made by academics to overcome these challenges. Conclusion. The study indicates that CBE is perceived as an important pedagogical approach in transforming health professions education, as it can align clinical training with the business plan of the university and the needs of the health system. However, for the successful implementation of CBE, full support from the university and the $\mathrm{DoH}$ is required.
\end{abstract}

Afr J Health Professions Educ 2018;10(2):129-135. DOI:10.7196/AJHPE.2018.v10i2.954

Community-based education (CBE) is a pedagogical approach that allows a student to develop professional skills in a community setting and gain a deeper understanding of patients in varied social and cultural contexts. ${ }^{[1]}$ From the literature, CBE is shown to be beneficial to students in various ways, including improved practical skills and clinical reasoning, increased self-confidence and development of a positive attitude toward patients. ${ }^{[2-5]}$ By experiencing real work situations, students develop a greater awareness of the responsibilities they have as health professionals. ${ }^{[4]}$ Through student placements in community-based settings, CBE is equally beneficial to communities, leading to improved access to healthcare and improved quality of care owing to the use of current practice techniques. ${ }^{[4,6]}$ Communities also benefit through home visits and health promotion activities that students undertake. ${ }^{[4]}$ Health systems have been noted to benefit from CBE, as students are seen to expand the workforce, especially in rural areas, where there is a scarcity of healthcare workers. ${ }^{[6]}$ Moreover, student CBE placements in rural areas have the potential to influence students' responsiveness to community needs and their future decisions to work in these areas. ${ }^{[4]}$ This can contribute to long-term benefits for the health system. Institutions of higher education that implement CBE programmes are viewed as demonstrating social accountability. ${ }^{[7]}$

Health professions education is undergoing major reform owing to two main external influences: (i) the Council for Higher Education (CHE) that advocates the integration of community engagement into curricula in the South African (SA) context; ${ }^{[8]}$ and (ii) the Lancet Commission that called for health professionals to graduate with appropriate competencies to be fully functional in a patient- and population-centred health system. ${ }^{[9]}$ Given this context, the University of KwaZulu-Natal (UKZN), Durban, SA strives for reform through its goal of responsible community engagement as outlined in its vision and mission statement. This goal aims to transform health professions education from one with a traditionally structured basis to one with a more competency-based focus that adds value to the communities it serves. ${ }^{[10]}$

To achieve this goal, the College of Health Sciences (CHS) at UKZN embarked on a business plan to adopt a primary healthcare curriculum (PHCC) to address service delivery and health professions training. ${ }^{[1]}$ The business plan proposes that a primary healthcare (PHC) approach be followed for all programmes offered by the CHS. ${ }^{[11]}$ In line with this approach, the CHS seeks to produce socially accountable, competent and relevant healthcare professionals with discipline-specific technical skills and generic higher education competencies and attributes. In this way, graduates become more responsive to provincial and national health priorities, the burden of disease and the health system. The CHS is therefore committed to offering community-based under- and postgraduate education. ${ }^{[1]}$

Community-based clinical training is seen as a valuable tool for transforming health professions education to meet graduate competencies and the needs of the health system. ${ }^{[9]}$ Therefore, to foster these competencies, UKZN creates learning opportunities for health professions students to engage in activities that can enable them to acquire these skills and values in community-based settings. In the literature, there are many studies highlighting students' experiences and views of $\mathrm{CBE}$, but there is a paucity of 
studies on the views of academics directly involved with the implementation of CBE. The objective of this study is to present the experiences and views of academics currently implementing community-based training in the CHS, UKZN.

\section{Methods \\ Research setting and context}

The CHS, UKZN comprises four schools: Clinical Medicine, Laboratory Medicine and Medical Sciences, Nursing and Public Health, and Health Sciences. The School of Health Sciences has eight disciplines: audiology, biokinetics, exercise and leisure sciences, dentistry, occupational therapy, optometry, pharmaceutical sciences, physiotherapy and speech-language pathology. Clinical training in these disciplines is done at campus clinics and designated off-campus sites. CBE is a prominent feature across all disciplines, but the level of participation differs. Moreover, as part of the business plan, disciplines are expected to send students to decentralised training sites, i.e. regional and district hospitals and community healthcare centres around these hospitals.

\section{Research design}

This was a descriptive, qualitative explorative study in which the intended role of community-based clinical training in the CHS was explored and the views of academics involved with $\mathrm{CBE}$ were described.

\section{Participants}

A purposive sampling method was used to select the study sample. The participants selected for the interviews included the college dean of teaching and learning, the academic leader of teaching and learning and the head of the Department of Family Medicine/Rural Medicine. They were selected for their expert opinion. One academic from each discipline in the School of Health Sciences was purposively selected for the focus group discussions. The researcher (IM) sent an invitational email to each participant. A total of 11 participants (A1 - A11) gave written informed consent to participate in the study.

\section{Data collection}

Data were collected by using a combination of interviews and focus group discussions. Firstly, the researcher conducted in-depth individual interviews with the dean and academic leader to gain a better understanding of the role of CBE and how it should be rolled out at discipline level. The researcher developed a set of leading questions to provide a relevant structure to the interviews (Table 1). The interviews focused on the policies and procedures for implementing $\mathrm{CBE}$, support and mechanisms for $\mathrm{CBE}$ and funding. Secondly, a separate face-to-face interview was held with an academic from the School of Clinical Medicine (the head of the Department of Family Medicine/Rural Medicine). The purpose of this interview was to obtain a better understanding of CBE experiences in other schools within the CHS. The interviews were scheduled at the interviewees' convenience and lasted $\sim 30$ minutes. Lastly, the researcher facilitated focus group discussions with academics representing each discipline. As all academics were not available simultaneously, two focus group discussions were held. The researcher developed a set of open-ended questions to guide the focus group discussions (Table 2). The discussions were related to their current $\mathrm{CBE}$ projects and how these added value to their clinical training practice, as well as the challenges experienced with implementation. The focus group discussions lasted $\sim 65$ minutes.

The researcher audio taped the interviews and focus group discussions. A research assistant transcribed the recordings verbatim and then performed

Table 1. Interviews with the dean and academic leader

Interview with dean
What is your view of community-based clinical training in the education process
of health professionals within the School of Health Sciences?
In your opinion, how will this add value to current teaching strategies for
clinical training in terms of meeting graduate competencies and meeting needs
of the health system?
What policies and procedures are in place for community-based clinical
training?
What mechanisms and support can the school provide for community-based
clinical training?
How will community-based clinical training be funded?
Interview with academic leader

What is your view of community-based clinical training in the education process of health professionals within the School of Health Sciences? In your opinion, how will this add value to current teaching strategies for clinical training in terms of meeting graduate competencies and needs of the health system?

What is the strategic operational plan present/envisioned by the School regarding community-based training of health professionals? How can disciplines within the school align to this plan?

How should community-based training be integrated into the current curriculum?

\section{Table 2. Focus group discussions with academics}

Kindly share your thoughts on the university's goal of community engagement and community-based education for health sciences students.

What are your views of how this can be implemented at discipline-specific level?

What is the current practice of community-based training in your discipline?

In your view, how does community-based teaching and learning add value to your current clinical training strategies?

In your opinion, how can community-based clinical training align with the primary health care curriculum model that aims to address service delivery and training of healthcare professionals?

In your view, how can community-based teaching align with the health professional graduate attributes in the various roles of healthcare practitioner, who is compassionate and culturally sensitive, communicator, collaborator, leader, scholar and advocator as envisioned by the College of Health Sciences?

From your experience, what are some of the challenges experienced in implementing community-based training? 
a data clean-up process. The researcher engaged the services of a research consultant to assist with the data analysis process. This consisted of data coding to identify particular features of the data set and sorting of the data, allowing themes and sub-themes to emerge from the respondents' statements according to Braun and Clarke's ${ }^{[12]}$ guide to thematic analysis. Credibility was established by the use of varied research methods, i.e. interviews and focus group discussions to obtain the data as well as peer debriefing. Another member of the research team conducted the peer debriefing by examining the data collection methods, processes, transcripts and data analysis procedures, and provided guidance to enhance the quality of the research findings. ${ }^{[13]}$ Transferability was facilitated by detailed description of the enquiry and purposive sampling. ${ }^{[14]}$ Transferability was further enhanced by comparing research findings with the current literature. Dependability was achieved by the use of a co-coder (research consultant) and confirmability was established through the direct quotation of interviewees. Participant confidentiality and anonymity were maintained.

\section{Ethical approval}

This study was part of a larger study conducted on CBE in the School of Health Sciences. Ethical clearance was obtained from the Humanities and Social Sciences Research Committee, UKZN (ref. no. HSS/1060/015D).

\section{Results and discussion}

Based on the responses of participants in the interviews and focus group discussions, three main themes emerged from the data analysis process: strengths of the community-based clinical training, challenges experienced and suggestions by academics.

\section{Strengths of community-based education}

This study revealed that academics viewed CBE as beneficial at multiple levels. The following section contains a selection of illustrative quotations of the benefits of community-based clinical training. The quotes are displayed on an institutional, student, health system and community level.

\section{Benefits to institution}

An academic reported that through CBE the institution could achieve its goal of responsible community engagement by producing socially accountable health professionals. It could create a platform for the institution to implement its policies and teaching strategies, as illustrated by the quotes in Table 3.
Related to its mission and vision statement, UKZN set out goals of being an academic institution actively engaged in redressing the disadvantages and imbalances of the past. ${ }^{[10]}$ The goal of responsible community engagement can be driven through CBE initiatives. By integrating $\mathrm{CBE}$ into the curriculum, the university is showing social accountability. This can contribute to the upliftment of the province by producing socially accountable health professionals and serving under-resourced communities. The literature also shows that higher education institutions with a socially accountable mandate can have a positive influence - not only on students but also on surrounding disadvantaged communities, leading to better health outcomes. ${ }^{[15]}$ Through implementation of policies and teaching strategies related to $\mathrm{CBE}$, the institution can be seen as facilitating the transition of traditional approaches of teaching to competency-based approaches that align training with the health needs of communities and the health system. ${ }^{[9]}$

\section{Benefits to students}

Academics believed that CBE could allow students to develop professionally. Students could improve clinical skills, proficiency and critical reasoning by being exposed to many patients. They could also learn by working closely with experienced colleagues in different clinical settings. At a deeper level, it could help them to relate theory to practice and acquire graduate competencies, such as compassion, better communication and leadership skills. These skills are not necessarily obtained in the classroom (Table 4).

It is well documented in the literature that CBE has been shown to enhance students' self-development, improving competence and confidence levels through increased patient exposure in community settings. ${ }^{[1]}$ Graduate competency can be defined as the acquisition and application of knowledge, clinical skills and values to provide effective care to patients. ${ }^{[1]}$ This study showed that CBE could create learning opportunities for students to acquire these attributes. These findings were similar to those of Mabuza et al., ${ }^{[16]}$ who indicated that the main focus of CBE was the learning of practical skills, professional behaviour and relating theory to practice. However, Ferris and $\mathrm{O}^{\prime} \mathrm{Flynn}{ }^{[17]}$ argue that for CBE to be more meaningful, students should not be left at these sites to acquire practical skills only; they should be given opportunities to self-reflect and self-assess, which can contribute to lifelong learning.

\section{Benefits to the health system}

According to academics, the health system could also be strengthened through CBE initiatives. Benefits included building sustainable partner-

Table 3. Benefits to the institution

\begin{tabular}{ll}
\hline Benefits & Participants' quotes \\
\hline $\begin{array}{l}\text { Meaningful community } \\
\text { engagement }\end{array}$ & 'We are trying to train competent, relevant, socially accountable health professionals. What better way than to let them \\
& go into the community... So we are giving back as a university and, as existing and potential healthcare professionals \\
& equally, we are gaining by being trained and fulfilling our criteria for our degree to practise as healthcare professionals.' \\
& (A1) \\
'It allows us to implement the policy frameworks of the Department of Health provincially, as well as nationally, and it & allows us as a college to really give effect to our own vision and mission whether it is the Teaching and Learning Office \\
and teaching and learning related to research to general university vision and mission and goals. I think we are in the & right place at the right time.' (A1) \\
& 'Community-based training requires a certain type of pedagogy of interactive participative learning. There are \\
frameworks and pedagogies that have been implemented in different programmes ... but I think we have got some & excellent examples of good practice that we can learn from each other and implement.' (A1)
\end{tabular}


ships, making healthcare more accessible to communities and aligning health professionals' training with the needs of the health system, which could make them easily employable (Table 5 ).

By collaborating with the Department of Health (DoH), a mutually beneficial relationship can be developed. The university will benefit, as their clinical training platforms could be significantly expanded. The DoH will benefit, as students could complement the current workforce in under-resourced areas, improving access to healthcare. This is further supported by Mabuza et al. ${ }^{[17]}$ - students are viewed as important members of the health team and appreciated and welcomed by communities.
Students exposed to CBE in rural areas could gain better insight to inequalities of healthcare and be motivated to return to these areas to seek employment. A study by Kaye ${ }^{[6]}$ shows that community-based clinical training changes students' attitudes towards rural practice and plays an important role in influencing graduates to work in underserved areas. Furthermore, students could have first-hand experience of how the health systems operate, facilitating their transition to the work environment. This finding is further supported by Knight, ${ }^{[18]}$ who found that students gained a better understanding of the policies and politics of clinics while in training.

\section{Table 4. Benefits to students}

\section{Benefits \\ Improving clinical skills \\ Acquiring critical reasoning \\ Learning from mentors Adapting to different work environment \\ Relating theory to practice \\ Applying primary healthcare principles \\ Providing appropriate care}

Achieving non-technical competencies

Opportunities for postgraduate studies

\section{Participants' quotes}

'Our students get to attend to more patients in the same time they attend to one patient at the clinical training site.' (A6)

'They also do not come in with a ready-made diagnosis ... Here they just have to think on their feet and problem solve on site.' (A5)

'They are also exposed to different supervisors with their own clinical expertise.' (A6)

'Working within the communities prepare the students for when they qualified ... they learn to work with what they have available.' (A6)

'The students will provide a service that they have already demonstrated theoretically that they have the knowledge and through the provision of the service they will develop the clinical competencies.' (A4)

'Students do a lot of broad-base promotive and preventive work throughout the communities.' (A7)

‘. it is also looking at what is relevant and appropriate for this context, not only socioeconomically but geographically. There is a focus on bringing in the family and the broader community where possible. Where there is somebody isolated at home, the rehab is focusing on the families sometimes, even the neighbours or community caregivers and using the resources that are in the community.' (A4)

'It is kind of startling to realise that the patient is a person who has a family and if they understand where the patient comes from they will treat them completely differently. There is a potential for a much deeper, nearly like an ontological shift that takes place.' (A3)

'... it is also adding value in terms of the non-clinical aspects. All those things like teaching them how to be leaders in an under-resourced environment, to communicate better when there is a language divide. We find that the campus-based, more resourced training environments were just letting them think in that sort of clinical, mechanical fashion, but now they are forced to be able to apply other skills in that context.' (A8)

'I do not think the university sufficiently teaches these competencies or tries to shift thinking in any way possible, we just want to get through the content of the curriculum. This is the right environment where we shift their thinking, where we mould them into what we would like them to be.' (A5)

'There are some postgrad projects at Master's and PhD levels where research is done in communities.' (A11)

\section{Table 5. Benefits to the health system}

Benefits

\section{Participants' quotes}

Building sustainable partnerships

'The business plan of community-based training and the primary healthcare model was developed in conjunction with the provincial Department of Health so it has the endorsement and support from key role players in terms of implementing it. So we will have the clinical training platforms with the department and hopefully we will have the staff to assist us in doing that.' (A1)

Making healthcare more accessible 'The focus is ideally on taking rehab services into the underserved. For example, for a mum with cerebral palsy child ... She might only get therapy once a month ... she might have to make two taxi trips to get there [local hospital]. If she is taking her child, that will be two taxi fares and if he is on a wheelchair that is a third fare. It is not about not having access, it is about the reality of that access ... ? (A4)

Learning how the health system operates 'They are actively going out and we have made an attempt to get them right down to clinic level and not just hospital level, so they understand how the health system works right from the start.' (A8)

Producing work-ready graduates ... with community-based training, we are trying to implement the policy frameworks and train our students such that they are capable of working in the primary healthcare environment equally well as they will be working in tertiary services for them to be proficient across the continuum.' (A1) 


\section{Benefits to communities}

Our study revealed that communities could benefit greatly from $\mathrm{CBE}$ initiatives. Most disciplines chose underserved communities to undertake their projects to provide or improve access and affordability to healthcare services (Table 6).

Our findings of benefits to communities were similar to those of Diab and Flack, ${ }^{[4]}$ who found that the primary benefit to communities was improved service delivery. By living in communities, students can become immersed with the realities of the communities. ${ }^{[7]}$ They can develop a better understanding of the disease burden and the social and cultural aspects that impact on health. Kelly et al. ${ }^{[5]}$ supported this finding that learning is developed by rich relationships with community members. Doherty and Couper ${ }^{[7]}$ indicated that through interaction with patient, family and community, students learn by exposure to an integrated primary healthcare experience. However, Diab and Flack ${ }^{[4]}$ argued that communities receive maximum benefits if the CBE initiatives are aligned with community needs. They also showed that it is important to engage community leaders before student placements to explain their function, as communities feel undermined if not informed of students' presence.

\section{Challenges}

This study shows that although academics embraced the pedagogical approach of community-based clinical training, they experienced challenges that could hinder implementation. The following section contains a selection of illustrative quotations of the challenges of community-based clinical training. The quotes below relate to challenges at university and DoH levels.

\section{Challenges at the university}

The challenges at the university included not having a clear operational plan, co-operation of all academics, support from the university and logistical issues.

No clear operational plan. At the university, the organisational structures are three-tiered: the college level, school level and discipline level. Although the business plan was being rolled out at college level, there seemed to be no clear operational plans or communication on how this had to be filtered down to individual disciplines in the school. While academics from individual disciplines believed that there should have been direction from college and school levels, academics from these levels believed that it should be driven by academics in individual disciplines, as illustrated by the following conflicting quotes:

'This clinical training model was conceptualised, and while it was good and we all supported it on theory, there was no situational analysis, ... no plan as to how we are going to roll it out based on the situational analysis; we cannot just say we have this plan ... the DoH needs help where our students get exposed. Let us just go and do it.' (A8)

Academics from college and school level firmly believed that:

'It is people from the ground, from various disciplines who are very passionate about this and who are committed people who will investigate it thoroughly, come out strategically, logistically, resourcefully draw up their own mandates with their own roles and responsibilities. So it is more bottom up. It will never be top down. It will be you having to push from the bottom and finding the ways of making things happen.' (A1)

Co-operation of all academics. Academics who represented individual disciplines in the focus group discussions believed that they were the only ones in their respective disciplines who were responsible for CBE. Other staff members seemed disinterested and if they were to leave, the CBE initiatives would fall apart:

'If I go, the project from my discipline will fall apart, that is unfortunate. We have become the face of the community ... if there is not a voice to speak for it, it falls apart because it is not entrenched in the curriculum. It is hard work and it is time consuming - that is why nobody wants to do it.' (A4)

Support from the university. There seemed to be a mismatch between the support given by the college and that received by academics. While academics at college and school level endorsed and supported CBE, academics involved in implementation thought otherwise:

'There needs to be supporting structures in place as much as they are saying the community outreach should have things in place for us, because lots of things we start and have to stop because of resources, etc.' (A4)

The study also highlighted that there were no incentives for staff participating in community engagement:

'Do we get rewarded for community engagement? Is there any structure for community engagement? We have got a research office; we have got a teaching and learning office. Is there an office for community engagement? ... it needs to be taken seriously.' (A3)

Logistical issues. The results of the study showed that many challenges were logistical in nature, including funding, limiting timetables, CBE being timeconsuming and community issues:

\begin{tabular}{|c|c|}
\hline Benefits & Participants' quotes \\
\hline Improving service delivery & $\begin{array}{l}\text { 'The priority is to offer a service to the underserved ... focus particularly on people, children largely with disability, } \\
\text { who either are unable to or have enormous challenges accessing the services that are available.' (A4) }\end{array}$ \\
\hline Committing to sustainable services & $\begin{array}{l}\text { 'It is important that we need continuity in a community. If you start providing a service, you must commit to it. We } \\
\text { cannot use the community only to take the students there, they start something and then we take them out. It is } \\
\text { also not fair to the community.' (A2) }\end{array}$ \\
\hline Promoting health in the communities & $\begin{array}{l}\text { 'Students engage directly with the community, determine their needs and do promotive and preventive work } \\
\text { outside of the clinic base.' (A7) }\end{array}$ \\
\hline Interacting with communities & $\begin{array}{l}\text { 'With the community home-stay project where for the rural block we offer some students to live in the community } \\
\ldots \text { students engage with host mothers ... they are quite motherly.' (A3) }\end{array}$ \\
\hline
\end{tabular}


Funding

'We have costs to consider when going out to communities. The main reasons we were pulled out of a very effective and established project was the cost to transport the students.' (A4)

'Even with us, the consumables that we require, the cost factor. A lot of our projects have a problem to sustain themselves because we do not have resources.' (A6)

\section{Timetables}

'We have a university timetable that does not allow for an integration of disciplines.' (A4)

\section{Time consuming}

'I had a student 2 weeks ago who wanted to go and do a follow-up assessment on a child. She cannot do that independently and the home visit is way into the community. The time now for me to go and observe and check on her means a whole morning.' (A4)

\section{Community, political and safety issues}

'We had followed everything in the book, the gatekeeper introduced us to everyone and the next thing, we got kicked out from our placement site which was a high school because of the political nature of the community. They thought we were aligned to someone who they were in conflict with. It was the gatekeeper himself. Although we were independent from him and he introduced us, but we got parcelled with him ... ? (A7)

Challenges at the university stem mainly from a lack of support from school and college level: support in the sense of effective communication down to discipline level, guidelines on how CBE programmes should be implemented, expectations and roles of academic staff and financial support. These challenges are not unique to this institution - similar challenges were noted in previous studies, with the main challenges being leadership support, funding and academics not willing to participate in the programme. ${ }^{[19]}$ Doherty and Couper ${ }^{[7]}$ found that CBE programmes are complex and time-consuming and require sustained hard work by committed academics. CBE is viewed as a mechanism for the university to demonstrate social accountability. The university should therefore provide the structure and support for successful implementation of this programme. It should also be supported by more academics within disciplines - not only those who have an interest in CBE.

\section{Challenges with the Department of Health}

The challenges experienced with the $\mathrm{DoH}$ were mainly due to clinical staff not clearly understanding their role in community-based training of students or not being aware of it. Academics were dependent on DoH staff for supervision of students, monitoring their attendance and writing reports on them at decentralised sites. However, there appears to be a lack of commitment from some clinical staff, and students were sometimes seen as a burden and impeding their work:

'There are perceptions from the $\mathrm{DoH}$ that this is an outside programme or an outside responsibility that is being imposed on them. There was no plan that was filtered down to the ground. There was this memorandum of understanding between the DoH and UKZN, but the people on the ground are not really aware of it.' (A8)
'We made arrangements with the head of department to supervise our students. He was very enthusiastic; however, other personnel were not so eager to supervise, as they felt that students slowed down their work pace.' (A6)

The challenges with the DoH were similar to those of the university in the sense of not having any guidance from higher authorities. This lack of support for clinical staff can be viewed as a missed opportunity for shared responsibility of this programme. This can hinder student learning at $\mathrm{DoH}$ sites, as it has been shown that staff enthusiasm for student supervision enhances student learning. ${ }^{[16]}$ It is important for academic staff to provide support for clinical staff in orientation and training of student supervision, as Archer ${ }^{[20]}$ noted that clinical supervisors changed their perceptions about student supervision after a short course designed by the university.

\section{Suggestions by academics}

The study revealed that academics viewed CBE as being extremely valuable and were eager to make it work, despite many challenges. The following are illustrative quotations of solutions they offered:

\section{No clear operational plan}

'There needs to be a core team. We need to sit together and come up with objectives for CBE training; this is the output and this is what we expect of the staff and students.'

'Without leadership, there is nobody steering the ship. Leadership is critical to develop or put together this framework so we can roll out this community-based teaching they expect from us.' (A10)

\section{Challenges with DoH}

'The one solution that we had was train the trainer. We bring all the clinical staff into the university, we get a workshop going and then we do programmes with them and then we do sessions at the end, where we get them to watch. We were thinking of getting videos and getting them to watch and assess so there is inter-reliability.' (A10)

'Maybe those trainers should be given some sort of honorary appointment or incentive for them being involved in the training of our students because they will tell you that look, I have queues to push ... ? (A9)

\section{Communication issues}

'There should also be good, open communication within the institutions and between the institutions, especially with the people on the ground who are directly involved with CBE programmes.' (A6)

This study shows that academics have the enthusiasm to drive the community-based clinical training agenda. SA health professions education is transforming ${ }^{[17]}$ and $\mathrm{CBE}$ is certainly a mechanism of change toward this transformation in making clinical training more meaningful in the SA context. Transformation is an ongoing process and academics should seize the opportunity for academic autonomy and control over CBE, as it has been shown to have great value in the education process of students in the health sciences. This is further supported by Doherty and Couper, ${ }^{[7]}$ who state that $\mathrm{CBE}$ programmes should be driven by champions within disciplines, especially if there is resistance from other staff. While there are committed academics from the institution, there should also be committed 
health professionals from the $\mathrm{DoH}$ supervising students at the teaching sites. CBE should be regarded as a shared responsibility of the collaborating institutions to ensure success and sustainability.

\section{Study limitations}

It is acknowledged that this study is limited to only one university and that the findings related to the views and opinions of academics who participated in the study are limited owing to their generalisability. Therefore, more research is required at other universities in SA to obtain wider, broad-based opinions of academics regarding $\mathrm{CBE}$.

\section{Conclusion}

The study indicates that $\mathrm{CBE}$ is perceived as an important pedagogical approach in transforming health professions education, as it can align clinical training with the business plan of the institution and the needs of the health system. Academics play a pivotal role and are seen as drivers of CBE. However, for the successful implementation of CBE, there needs to be full support from the university and DoH to overcome any challenges that may arise.

\section{Acknowledgements. None.}

Author contributions. IM was responsible for data collection, data analysis and conceptualisation. SS was responsible for refining the methodology and overseeing the write-up.

\section{Funding. None.}

Conflicts of interest. None.

1. Skelton J, Raynor MR, Kaplan AL, et al. University of Kentucky community-based field experience: Program description. J Dent Educ 2001;65:1238-1242.
2. Eaton KA, de Vries J, Widstrom E, et al. 'Schools without walls?' Developments and challenges in dental outreach teaching - report of a recent symposium. Eur J Dent Educ 2006;10(4):186-191. https://doi.org/10.1111/j.1600-05 79.2006.00411.x

3. Piskorowski WA, Stefanac S, Fitzgerald M, Green TG, Krell R. Influence of community-based dental education on dental students' preparation and intent to treat underserved populations. Dent Educ 2012;76:534-539.

4. Diab P, Flack P. Benefits of community-based education to the community in Southern African health science facilities. Afr J Prim Health Care Fam Med 2013;5(1). https://doi.org/10.4102/phcfm.5i1.474

5. Kelly L,Walters L, Rosenthal D. Medical education: Is success a result of meaningful personal learning experiences? Educ Health 2014;27(1):47-50. https://doi.org/10.4103/1357-6283.134311

6. Kaye DK, Mwanika A, Sewankombo N. Influence of the training experience of Makerere University medical and nursing graduates on willingness and competence to work in rural health facilities. Rural Remote Healt 2010;10:1372.

7. Doherty JE, Couper I. Strengthening rural health placement for medical students: Lessons for South Africa from international experiences. S Afr Med J 2016;6(5):524-527. https://doi.org/10.7196/SAMJ./2016.v106i5

8. Centre for Higher Education, Higher Education Quality Committee, South Africa. Criteria for Institutional Audits. Pretoria: CHW, 2004.

9. Frenk J, Chen L, Bhutta ZA, et al. Health professionals for a new century: Transforming education to strengthen health systems in an interdependent world. Lancet 2010;376(9756):1923-1958. https://doi.org/10.1016/s01406736(10)61854-5

10. University of KwaZulu-Natal. Vision and mission statement. Durban, South Africa. http://www.ukzn.ac.za (accessed 13 April 2018).

1. Essack S. Draft business plan: Community based training in primary health care model in School of Healt Science. Durban: UKZN, 2014.

12. Braun V, Clarke V. Using thematic analysis in psychology. Qual Res Psychol 2006;3(2):77-101. https:/doi. org/10.1191/1478088706qp063oa

13. Pitney WA, Parker J. Qualitative Research in Physical Activity and the Health Professions. Auckland, New Zealand: Human Kinetics, 2009.

14. Bitsch V. Qualitative research: A grounded theory example and evaluation criteria. J Agribus 2005;23(1):75-91.

15. Reeve C, Woolley T, Ross SJ, et al. The impact of socially-accountable health professional education: A systematic review of the literature. Med Teach 2017;39(1):67-73. https://doi.org/10.1080/0142159X.2016.1231914

16. Mabuza LH, Diab P, Reid SI, et al. Communities' views, attitudes and recommendations on community-based 6. Mabuza LH, Diab P, Reid S S, et al. Communities views, attitudes and recommendations on community-based
education of undergraduate health sciences students in South Africa: A qualitative study. Afr J Prim Health Care Fam Med 2013;5(1). https://doi.org/10.4102/phcfm.v5i1.456

17. Ferris H, O'Flynn D. Assessment in medical education. What are we trying to achieve? Intern J High Educ 2015;4(2):139-144. https://doi.org/10.5430/ijhe.v4n2p139

18. Knight GW. Community-based dental education of University of Illinois, Chicago. J Dent Educ 2011;75(10) (Suppl):S14-S20.

19. Abu-Rish E, Kim S, Choe L, et al. Current trends in interprofessional education of health sciences students: A literature review. J Interprof Care 2012;6(6):444-451. https://doi.org/10.3109/13561820.2012.715604

20. Archer E. Improving undergraduate clinical supervision in a South African context. Afr J Health Professions Educ 2011;3(2):6-8.

Accepted 5 October 2017. 